\title{
Prototipe Pengendalian pH dan Elektro Konduktivitas Pada Cairan Nutrisi Tanaman Hidroponik
}

\author{
Anwar Mujadin $^{1}$, Dwi Astharini ${ }^{2}$, Octarina Nur Samijayani ${ }^{3}$ \\ ${ }^{1}$ Teknik Elektro, Fakultas Sains dan Teknologi, Universitas Al Azhar Indonesia, Komplek Masjid \\ Agung Al Azhar Kebayotan Baru, Jakarta Selatan 12110 \\ Penulis untuk Korespondensi/E-mail: amujadin@uai.ac.id
}

\begin{abstract}
Abstrak - Prduk komuditas budidaya cara hidroponik saat ini hasilnya belum optimal, ini disebabkan karena pemberian nutrisi pada tanaman hidroponik masih diperlakukan sama untuk semua jenis tanaman. Padahal setiap tanaman memiliki karakteristik sendiri terhadap nutrisi yang diserapnya. Parameter keberhasilan budidaya tanaman hidroponik tergantung pada pH dan densitas (kekentalan) dari cairan nutrisi yang diberikan. Dalam tulisan ini akan dijelaskan mengenai rangkaian elektronika pengukuran $\mathrm{pH}$ dan densitas nutrisi tanaman hidroponik. Hasil pengujian prototipe mampu diterapkan pada pembacaan pH 5-9 dengan resolusi $0.63 \mathrm{~V} / \mathrm{pH}$ dan electro conductivitas sebesar $Y=2900 \mathrm{e}{ }^{\mathrm{X}}$.
\end{abstract}

Kata Kunci - Hidroponik, pH dan Masa jenis dari nutrisi tanaman hidroponik

Abstract - Currently, commodity product of hydroponics plant has not optimal yet caused by giving nutrients in hydroponic plants are still treated equally for all types of plants. Whereas each plant had own characteristics of the nutrients absorbed. pH meter and viscosity(electro conductivity) are the parameters decided for growing plant. In this paper will be explained clearly of electronics circuit pH measurement and electro conductivity. At eksperiment prototipe can be reading at $\mathrm{pH} 5-9$ with resolution $0.63 \mathrm{~V} / \mathrm{pH}$ and electro conductivitas at $Y=2900 e^{-}$.

Keywords - Hydroponics, $p H$ and Density of liquid nutrient plant

\section{PENDAHULUAN}

$\mathrm{H}$ idroponik adalah salah satu metode bercocok tanam yang menggunakan media selain tanah dan dapat diaplikasikan pada area yang sempit. Awalnya, banyak sekali kontroversi mengenai kelebihan dan kekurangan hidroponik terutama saat metode ini pertama kali diperkenalkan. Walaupun begitu, tidak dapat dipungkiri bahwa metode hidroponik memberikan penyegaran dan juga solusi baru bagi orang-orang yang tinggal di daerah perkotaan untuk bisa merasakan sensasi bercocok tanam di lahan yang terbatas. Saat ini penerapan bercocok tanam sudah banyak dilakukan masyarakat Indonesia, terutama di daerah sentra agrobisnis.
Di Indonesia saat ini bercocok tanam dengan cara hidroponik hasilnya belum optimal, ini disebabkan karena pemberian nutrisi pada tanaman hidroponik masih diperlakukan sama untuk semua jenis tanaman. Padahal setiap tanaman memiliki karakteristik sendiri terhadap nutrisi yang diserapnya. Tidak adanya ketimbangan antara $\mathrm{pH}$ dan electro conductivity (EC) membuat tanaman, justru menjadi "keracunan" dan mati akibat pemberian dosis nutrisi yang tidak tepat.

Pada tulisan ini akan dibahas mengenai rangkaian kendali elektronika untuk penentuan nilai $\mathrm{pH}$ dan EC hasil penelitian. Prototipe mampu mengukur nutrisi tanaman hidroponik terutama $\mathrm{pH}$ dan EC secara persisi dan akurat. 


\section{TINJAUAN PUSTAKA}

\section{Pengertian Tanaman Hidroponik}

Hidroponik adalah salah satu metode bercocok tanam yang menggunakan media selain tanah dan dapat diaplikasikan pada area yang sempit. Jenis teknis budidaya tanaman hidroponik dengan sistem tower saat ini sangat dimininati, karena tanaman hidroponik diletakan pada sebuah wadah (paralon) vertikal yang memungkinkan perlu lahan yang sangat sempit. Pada tanaman hidroponik vertikal tower, caian nutrisi diteteskan pada puncak tower sedikit demi sedikit. Sebagian nutrisi akan diserap oleh akar tanaman sebagian lagi jatuh kedasar paralon untuk siap dipompakan lagi keatas tower.

Pada Gambar 1 diperlihatkan tanaman hidroponik dengan teknis tower pada area yang sangat sempit [1].

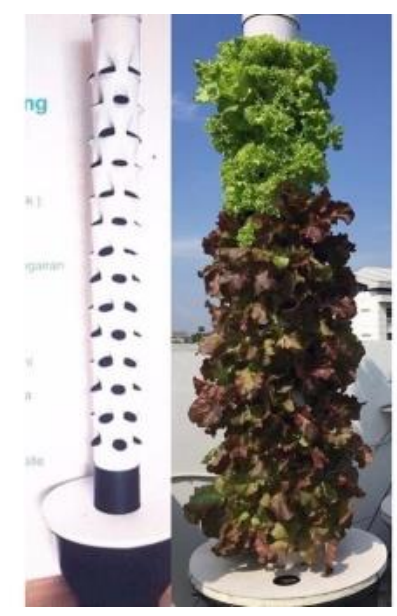

Gambar 1. Tanaman hidroponik dengan vertikal tower pada area yang sangat sempit [1].

\section{Hidroponik Kontroler}

Hidroponik kontroler adalah sebuah sistem pengendali umumnya untuk pengkondisian tanaman hidroponik seperti habitat aslinya. Pada Gambar 2 diperlihatkan sistem pengendali pengkondisian tanaman hidroponik [2].

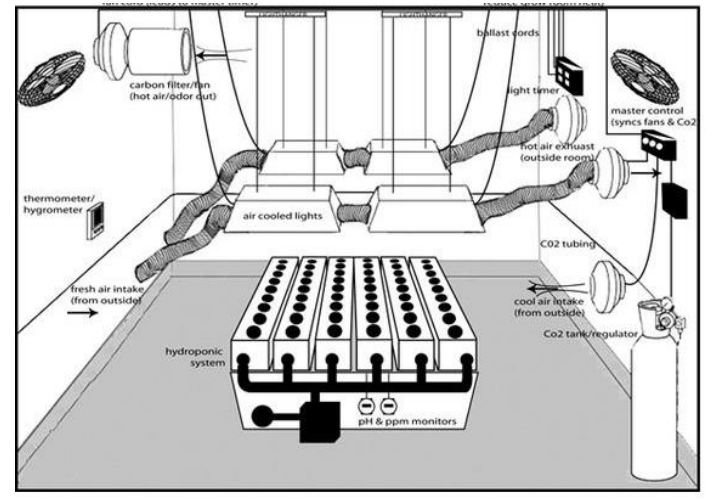

Gambar 2. Sistem pengendali pengkondisian tanaman hidroponik [2].

Pengkondisian ada dua macam yaitu pertama pengkondisian sekitar tanaman seperti suhu, humudity, gas $\mathrm{CO} 2$, dan intensitas cahaya. Kedua pengkondisian dari nutrisi yang diberikan melalui akar tanaman hidroponik.

\section{pH Meter}

Alat untuk mengukur tingkat keasaman maupun kebasaan larutan dapat diukur menggunakan $\mathrm{pH}$ meter. Prinsip kerja utama $\mathrm{pH}$ meter adalah terletak pada sensor probe berupa elektrode kaca (glass electrode) dengan jalan mengukur jumlah ion $\mathrm{H} 3 \mathrm{O}+$ di dalam larutan.

Elektroda diisi dengan larutan $\mathrm{HCl} \quad(0,1$ $\mathrm{mol} / \mathrm{dm} 3$ ). Di dalam larutan $\mathrm{HCl}$, terendam sebuah kawat elektrode panjang berbahan perak yang pada permukaannya terbentuk senyawa setimbang $\mathrm{AgCl}$. Gambar 3 diperlihatkan skema sistem elektrode kaca [3].

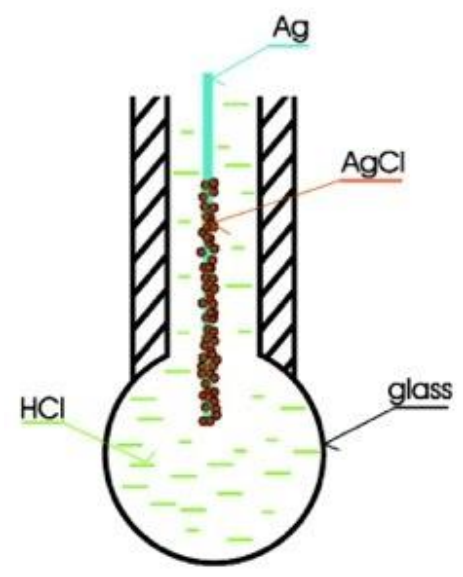

Gambar 3. Skema sistem elektrode kaca pH probe 
Inti sensor $\mathrm{pH}$ terdapat pada permukaan bulb kaca yang memiliki kemampuan untuk bertukar ion positif $(\mathrm{H}+)$ dengan larutan terukur. Kaca tersusun atas molekul silikon dioksida dengan sejumlah ikatan logam alkali. Pada saat bulb kaca ini terekspos air, ikatan $\mathrm{SiO}$ akan terprotonasi membentuk membran tipis $\mathrm{HSiO}+$ sesuai dengan reaksi berikut:

$\mathrm{SiO}+\mathrm{H}_{3} \mathrm{O}+\rightarrow \mathrm{HSiO}++\mathrm{H}_{2} \mathrm{O}$

Pada permukaan bulb terbentuk semacam lapisan "gel" sebagai tempat pertukaran ion $\mathrm{H}+$. Jika larutan bersifat asam, maka ion $\mathrm{H}+$ akan terikat ke permukaan bulb. Pertukaran ion hidronium $(\mathrm{H}+)$ yang terjadi antara permukaan bulb kaca dengan larutan sekitarnya inilah yang menjadi kunci pengukuran jumlah ion $\mathrm{H}_{3} \mathrm{O}+$ di dalam larutan. Kesetimbangan pertukaran ion yang terjadi di antara dua fase dinding kaca bulb dengan larutan, menghasilkan beda potensial di antara keduanya. Pada Gambar 4 diperlihatkan kurva perubahan $\mathrm{pH}$ dengan beda potensial [3]

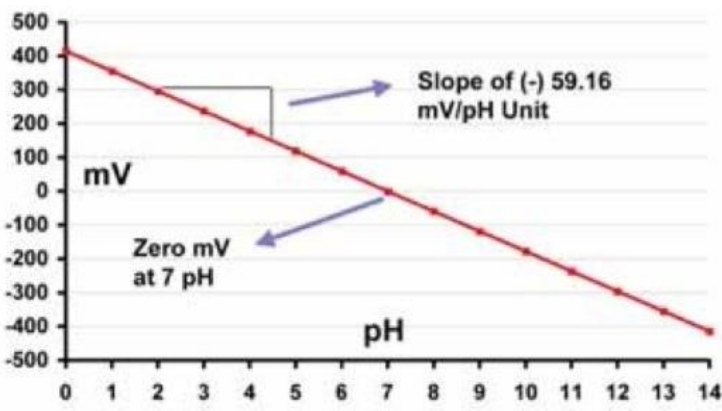

Gambar 4. Kurva perubahan $\mathrm{pH}$ dengan beda potensial [4]

\section{Electric Conductivity (EC)}

Conductivity meter adalah alat untuk mengukur nilai konduktivitas listrik (electric conductivity) suatu larutan atau cairan. Nilai konduktivitas listrik sebuah zat cair menjadi referensi atas jumlah ion serta konsentrasi padatan (total dissolved Solid, TDS) yang terlarut di dalamnya. Pada Gambar 5 diperlihatkan conductivity meter [4].

Bila $\mathrm{V}$ adalah tegangan listrik rangkaian (Volt), I untuk arus listrik rangkaian (Ampere), dan $\mathrm{R}$ untuk tahanan listrik rangkaian $(\Omega)$.

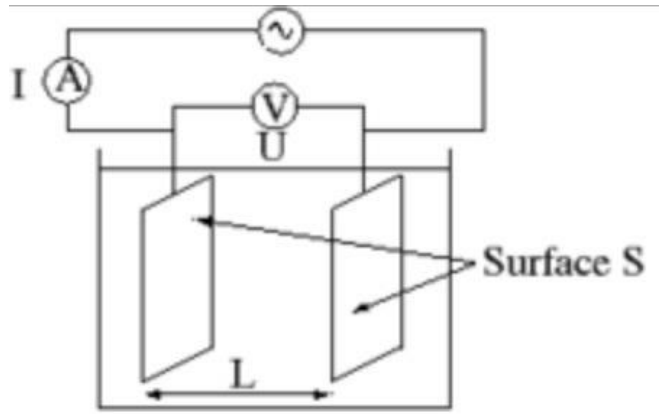

Gambar 5. Conductivity meter [4]

Tahanan listrik (R) berbanding lurus dengan jarak antara dua elektrode (L) conductivity meter, dan berbanding terbalik dengan luas area elektrode (A; pada gambar di atas S). dari formulasi didapat:

$$
\mathrm{R}=(\mathrm{L} / \mathrm{A}) \times \rho
$$

Karena ( L/A ) adalah konstan dan bisa disimbolkan menjadi $\mathrm{C}$ maka:

$\mathrm{R}=\mathrm{C} \times \rho$

Dimana $\rho$ adalah tahanan listrik spesifik ( $\Omega . m)$ larutan. Atau bisa ditulis :

$\mathrm{R}=\mathrm{V} / \mathrm{I}=(\mathrm{L} / \mathrm{A}) \mathrm{x} \rho=\mathrm{C} \times \rho$

Conductivity meter sebenarnya mengukur konduktivitas listrik spesifik (specific conductivity). Konduktivitas listrik spesifik adalah nilai konduktivitas listrik untuk tiap satu satuan panjang. Konduktivitas listrik spesifik ini disimbolkan dengan $\kappa$ (Kappa), adalah kebalikan dari tahanan listrik spesifik $(\rho)$ :

$$
\kappa=1 / \rho
$$

Dimana konduktivitas listrik spesifik menggunakan satuan $\mathrm{S} / \mathrm{m}$ (Siemens per meter). Dan jika persamaan (2.5) dimasukkan ke dalam persamaan (2.4), didapat:

$$
\kappa=\mathrm{C} \times \mathrm{I} / \mathrm{V}
$$

Besar tegangan listrik (V) ditentukan oleh sistem, besar arus listrik (I) adalah parameter yang diukur, serta konstanta (C) didapatkan sebelumnya dari proses kalibrasi conductivity meter dengan menggunakan larutan yang diketahui nilai konduktivitas spesifiknya [4]. 


\section{METODE PENELITIAN}

Merancang bangun sebuah prototipe pengukur $\mathrm{pH}$ dan densitas (EC) cairan nutrisi tanaman hidroponik. Teknis kalibrasi dan pada kedua alat ukur. Teknis pengambilan sampel untuk mendapatkan densitas cairan nutrisi pada pengujian EC.

\section{RANCANG BANGUN PERANGKAT KERAS}

\section{pH Meter}

Rangkaian $\mathrm{pH}$ meter hasil penelitian diperlihatkan pada Gambar 6 :

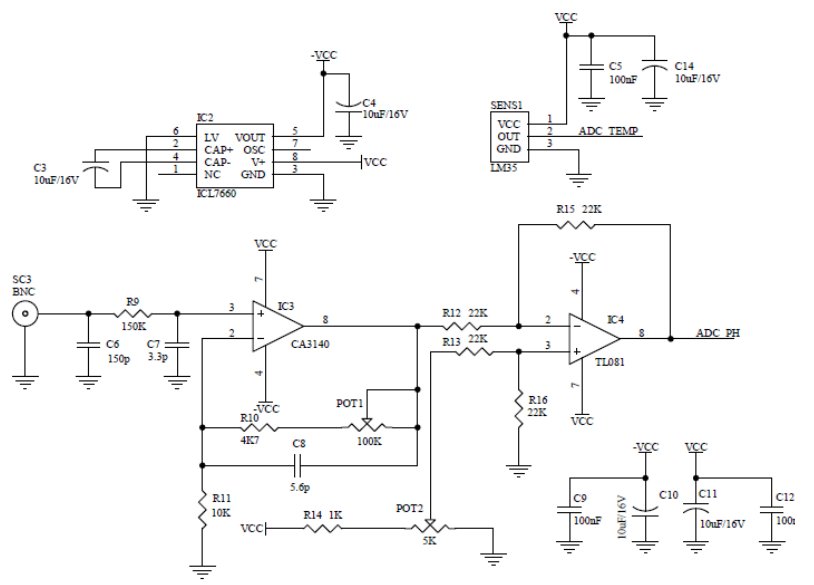

Gambar 6. Rangkaian pH meter

Formulasi rangkaian diturunkan menjadi:

$$
\text { Vout }=\left(\frac{\text { POT2 }}{\text { POT2 }+ \text { R14 }}\right) \cdot \mathrm{VCC}-\left(\frac{\mathrm{POT} 1+\mathrm{R} 10}{\mathrm{R} 11}+1\right) \cdot \mathrm{Vin}
$$

Vin adalah tegangan masukan dari probe $\mathrm{pH}$ meter (SC3) dan Vout adalah tegangan keluaran dari Opamp subtractor (IC4, pin 8). Karena tegangan keluaran Vout hasilnya harus positif maka:

$$
\left(\frac{\mathrm{POT} 2}{\mathrm{POT} 2+\mathrm{R} 14}\right) \cdot \mathrm{VCC} \geq\left(\frac{\mathrm{POT} 1+\mathrm{R} 10}{\mathrm{R} 11}+1\right) \cdot \mathrm{Vin}
$$

Bila Nilai :

$$
\left(\frac{\mathrm{POT} 2}{\mathrm{POT} 2+\mathrm{R} 14}\right) \cdot \mathrm{VCC}=\frac{1}{2} \mathrm{VCC}
$$

maka nilai resistansi potensiometer POT2 = $\mathrm{R} 14=1 \mathrm{~K} \Omega$. VCC adalah tegangan catudaya untuk mikrokontroller dan seluruh rangkaian elektronika sebesar +5 Vdc. Sehingga :

$$
\text { Vout }=2.5-\left(\frac{\text { POT1 }+ \text { R10 }}{\mathrm{R} 11}+1\right)
$$

Dengan penguatan probe $\mathrm{pH}$ sebesar:

$$
\left(\frac{\mathrm{POT} 1+\mathrm{R} 10}{\mathrm{R} 11}+1\right)=\left(\frac{100 \mathrm{~K}+4 \mathrm{~K} 7}{10 \mathrm{~K}}+1\right)=11.47
$$

Sehingga laju probe $\mathrm{pH}$ meter penguatan berlaku hanya dari $0 \mathrm{~V}$ sampai $2.5 \mathrm{~V}$.

POT1 diatur dibatasi antar antara $\mathrm{pH} 5$ sampai pH 9 (untuk hidroponik). Pada Gambar 7 diperlihatkan grafik pembacaan $\mathrm{pH}$ meter sesuai dengan tuning POT1.

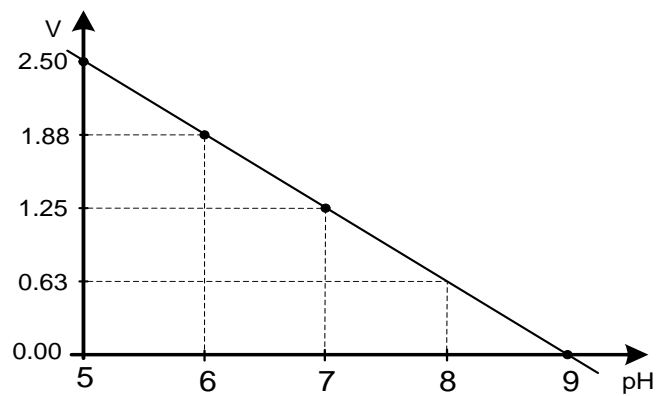

Gambar 7. Grafik pembacaan $\mathrm{pH}$ meter sesuai dengan tuning POT1.

Dari Gambar 7. pada grafik terlihat $\mathrm{pH} 7$ berada pada tegangan $1.25 \mathrm{~V}$.

Pada Gambar 8 diperlihatkan overlay komponen elektronika $\mathrm{pH}$ meter

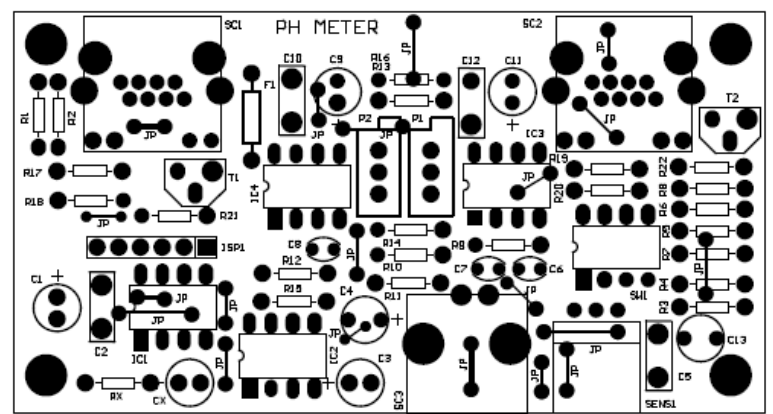

Gambar 8. Overlay komponen elektronika pH meter

Pada Gambar 9 diperlihatkan wujud fisik dari $\mathrm{pH}$ meter hasil penelitian setelah dirakit dan di test. 


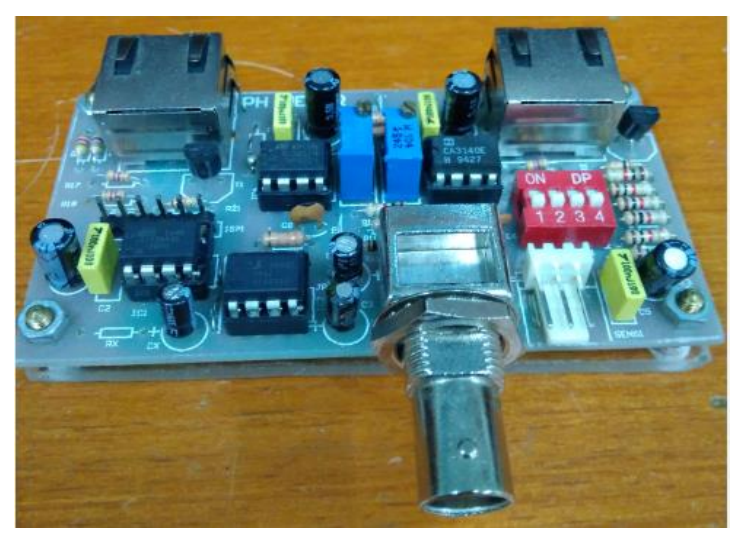

Gambar 9. Wujud fisik dari pH meter hasil penelitian

\section{EC Meter}

Rangkaian EC meter hasil penelitian diperlihatkan pada Gambar 10.

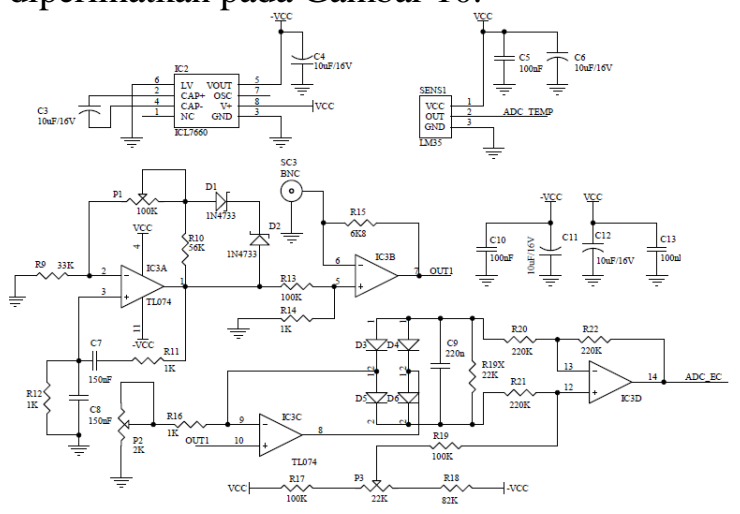

Gambar 10. Rangkaian EC meter

Pada Gambar 10, IC3A adalah rangkaian square wave generator pada frekuensi osilasi sebesar:

$$
\text { fout }=\frac{1}{2 \pi \cdot R 12 \cdot C 8}=\frac{1}{2 \pi \cdot R 11 \cdot C 7}=\frac{1}{2 \cdot 3,14 \cdot 10^{3} \cdot 150^{-9}}=10 \cdot 62 \mathrm{~Hz}
$$

Dengan amplitude keluaran sebesar $\pm 5 \mathrm{~V}$. IC $3 \mathrm{C}$ dan D3-D6 membentuk rangkaian penyearah gelombang penuh dengan tegangan keluaran rata-rata sebesar:

$$
\begin{gathered}
\mathrm{Vrms}=\mathrm{Vm} \times 0.7071=5 \times 0.7071=3.5355 \mathrm{~V} \\
\mathrm{~V}_{\mathrm{DC}} \text { rata-rata }=0.45 \times 3.5355=1.6 \mathrm{~V}
\end{gathered}
$$

Potensiometer P2 dan R16 sebagai pembagi tegangan $\mathrm{V} 1$ dari $0-1.6 \mathrm{~V}$ yang dituning melalui P2. Rangkaian R17, P3 dan R16 sebagai pembagi tegangan V2 dituning pada tegangan $3 \mathrm{~V}$ oleh P3. IC3 digunakan sebagai rangkaian subtractor dengan tegangan keluaran Vout (pin 14) sebesar :

$$
\text { Vout }=\text { V2-V1= 3-V1 Volt. }
$$

Nilai V1 tergantung pada besaran densitas nutrisi hidroponik antara 0-1.6 Volt.

Dari hasil percobaan 1-10 (P1-P10), pupuk Nutrisi $A B$ mix 10 gram dicampur dengan 1 liter air membentuk cairan nutrisi P1. Selanjutnya cairan nutrisi P1 diencerkan 2 kali dengan penambahan air 1 liter membentuk cairan nutrisi P2. Begitu seterusnya sampai mendapatkan cairan nutrisi P10.

Pada Gambar 11 diperlihatkan grafik hasil pengukuran antara besaran tegangan keluaran (Vout) terhadap densitas cairan dalam part per million ( $\mathrm{ppm}$ ) dikalibrasi menggunakan TDS meter HM Digital meter pada cairan uji nutrisi P1sampai dengan P10.

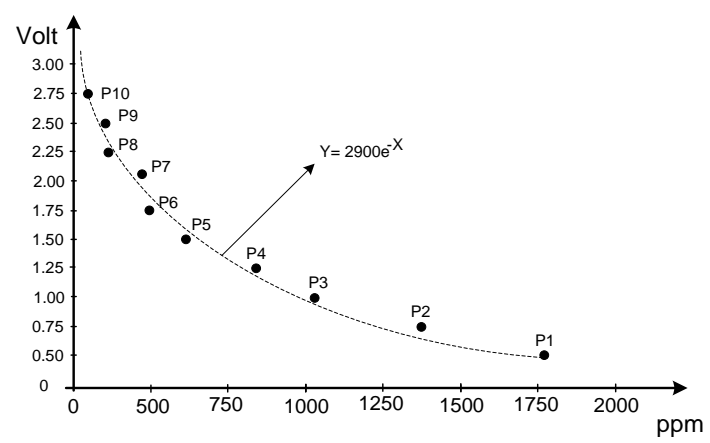

Gambar 11. Grafik hasil pengukuran besaran tegangan terhadap densitas cairan dalam ppm.

Secara matematis pada Gambar 11, dapat didekatkan persamaan garis lengkung dengan persamaan eksponensial:

$$
\mathrm{Y}=2900 \mathrm{e}^{-\mathrm{X}}
$$

Pada Gambar 12 diperlihatkan overlay komponen elektronika EC meter

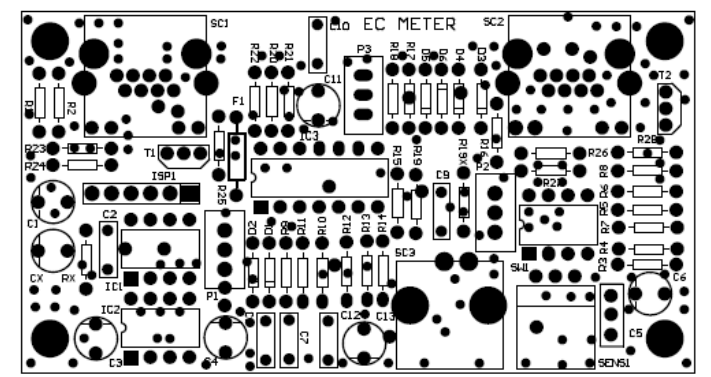

Gambar 12. Overlay komponen elektronika EC meter 
Pada Gambar 13 diperlihatkan wujud fisik dari EC meter hasil penelitian setelah dirakit dan di test.

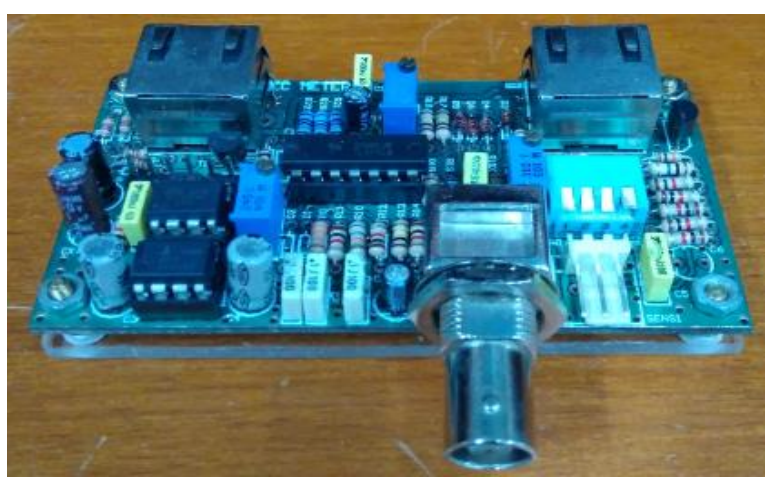

Gambar 13. Wujud fisik dari EC meter hasil penelitian

\section{KESIMPULAN}

Telah berhasil merancang bangun sebuah prototipe Pengendalian $\mathrm{pH}$ dan Elektro Konduktivitas Pada cairan nutrisi tanaman hidroponik.

$\mathrm{pH}$ meter dirancang pada referensi $2.5 \mathrm{~V}$ dengan penguatan probe $\mathrm{pH}$ sebesar 11.47 kali pada jangkah pembacaan antara $\mathrm{pH}$ 5- $\mathrm{pH}$ 9. Jangkah pengukuran $\mathrm{pH}$ dapat di-adjust lebih luas dengan merubah tegangan referensi pada POT2.

EC meter dirancang pada frekuensi kerja 10.62 $\mathrm{Hz}$ dengan tegangan keluaran $\mathrm{DC}$ rata-rata sebesar 1.6V. ditembakan pada media cairan nutrisi membentuk tegangan keluaran sebesar 1.4V-3V. Setelah dikalibrasi menggunakan HM digital TDS meter, hasil pengujian menunjukan EC meter mampu membaca kerapatan cairan nutrisi dari 750 ppm- 1750 ppm membentuk persamaan matematis eksponensial dengan pendekatan sebesar $\mathrm{Y}=2900 \mathrm{e}^{\mathrm{X}}$, dimana $\mathrm{Y}$ adalah nilai ppm dan $\mathrm{X}$ adalah besaran tegangan keluaran EC meter. Jangkah pengukuran EC dapat di-adjust lebih luas dengan merubah tegangan referensi pada $\mathrm{P} 3$.

\section{UCAPAN TERIMA KASIH}

PENELITIAN INI DIDUKUNG OLEH PRODI ELEKTRO FAKULTAS SAINS DAN TEKNOLOGI UNIVERSITAS AL AZHAR INDONESIA DARI RESEARCH GRANT INTERNAL LP2M UAI

\section{DAFTAR ACUAN/PUSTAKA}

[1] http://www.tipsberkebun.com/kelebihandan-kekurangan-bercocok-tanamhidroponik.html, (Diakses pada 1 November 2016)

[2] http://www.tecniccat.com/productos/hydro ponic_plus_eng/, (Diakses pada 1 November 2016).

[3] http://artikel-teknologi.com/prinsip-kerjaph-meterl, (Diakses pada 2 November 2016).

[4] http://artikel-teknologi.com/prinsip-kerjaconductivity-meter/, (Diakses pada 2 November 2016) 